\title{
PURWARUPA APLIKASI BERGERAK UNTUK MENDUKUNG EFEKTIFITAS PEMBELAJARAN MATEMATIKA SEKOLAH MENENGAH PERTAMA
}

\author{
Moh. Munih Dian Widianta \\ Hendra Yufit Riskiawan \\ Tutut Hidayati Munawaroh \\ (Jurusan Teknologi Informasi Politeknik Negeri Jember)
}

\begin{abstract}
Abstrak
Perkembangan teknologi telepon selular semakin pesat, ini dapat dibuktikan dengan banyaknya teknologi telepon seluler yang dikembangkan untuk memenuhi kebutuhan masyarakat. Teknologi yang sangat dominan dalam pertumbuhan telepon seluler adalah sistem operasi Android. Sistem ini memungkinkan pengembang aplikasi untuk mengembangkan aplikasi yang dibuat. Android merupakan platform mobile pertama yang memiliki fitur relatif lengkap, terbuka dan bebas. Lengkap dalam penyediaan peralatan dalam membangun software, terbuka dalam kebebasan mengembangkan aplikasi, bebas yang berarti dapat didistribusikan dan diperdagangkan dalam bentuk apapun.

Pesatnya perkembangan teknologi tersebut dan banyaknya pengguna telepon seluler utamanya dikalangan pelajar, sangat potensial untuk dimanfaatkan berbagai kebutuhan yang mendukung pembelajaran. Untuk menjawab kebutuhan tersebut, melalui penelitian ini dibangun purwarupa aplikasi pembelajaran matematika untuk siswa SMP berbasis android yang didalamnya terdapat materi beserta soal latihan yang ditampilkan secara menarik dan interaktif agar dapat membantu guru untuk memantapkan pembelajaran yang telah diperoleh di kelas. Selain itu aplikasi bergerak ini diharapkan dapat membantu siswa agar lebih mengerti dan memahami serta dapat menumbuhkan rasa ketertarikan siswa terhadap mata pelajaran matematika. Selain tentunya ikut membantu perkembangan pendidikan di Indonesia.
\end{abstract}

Keywords - Aplikasi Bergerak, Media Pembelajaran Matematika, Android.

\section{Pendahuluan}

Matematika adalah ilmu dasar yang memiliki peran penting dalam ilmu pengetahuan dan teknologi. Matematika berperan untuk mempersiapkan siswa agar sanggup menghadapi perubahan keadaan yang berkembang melalui tindakan dasar pemikiran kritis, rasional dan cermat serta dapat menggunakan pola pikir matematika baik dalam mempelajari berbagai ilmu pengetahuan maupun dalam kehidupan sehari-hari.

Matematika merupakan salah satu mata pelajaran di sekolah yang dinilai cukup memegang peranan penting dalam membentuk siswa menjadi berkualitas. Pentingnya mempelajari pelajaran matematika tingkat Sekolah Menengah Pertama mulai dasar yaitu agar di tingkat selanjutnya tidak mengalami kesulitan untuk memahaminya. Pembelajaran yang monoton didalam kelas, seringkali membuat siswa merasa jenuh dengan rumus-rumus yang begitu banyak yang harus mereka pelajari.

Media pembelajaran matematika yang ada sekarang tersedia dalam beberapa bentuk diantaranya dalam bentuk buku dan website $(e-$ learning). Diantara ke dua bentuk media tersebut memiliki banyak kekurangan yaitu buku mudah rusak terkena air atau robek sedangkan website $(e-$ learning) memiliki kekurangan untuk mengaksesnya yang harus menggunakan media komputer. Aspek mobilitasnya kurang karena komputer tidak mudah dibawa kemana-mana. Saat ini teknologi telepon pintar telah berkembang pesat dengan berbagai macam sistem operasi dan salah satu paling populer adalah Android.

Permasalahan yang muncul dapat mengakibatkan menjadi kurang pahamnya siswa terhadap materi atau pelajaran yang diajarkan sehingga dapat berdampak pula pada

Halaman 1 dari 6 
berkurangnya minat siswa terhadap pelajaran matematika itu sendiri.

Solusi yang ditawarkan adalah dengan menggunakan teknik atau metode pembelajaran yang baru yang bisa disesuaikan dengan memanfaatkan teknologi yang sudah berkembang. Aplikasi ini memiliki kelebihan diantaranya guru atau pengguna dapat mengunggah materi dan kuis, sehingga siswa tidak merasa bosan saat mengerjakan soal selain itu guru dapat menyesuaikan dengan kurikulum terbaru. Soalsoal yang disajikan terdapat gambar-gambar menarik seperti komik yang dapat menarik minat belajar siswa. Mudah dibawa kemana-mana karena terinstal dengan telepon seluler yang notabene adalah alat komunikasi sehari-hari. Dengan adanya aplikasi ini diharapkan dapat memotivasi para siswa agar giat belajar.

\section{Metodologi}

Metode pengembangan sistem yang digunakan yaitu dengan metode Prototype. Menurut Roger S. Pressman (1997) metode Prototype melewati tiga proses, yaitu pengumpulan kebutuhan, perancangan, dan evaluasi Prototype. Proses-proses tersebut dapat dijelaskan sebagai berikut:

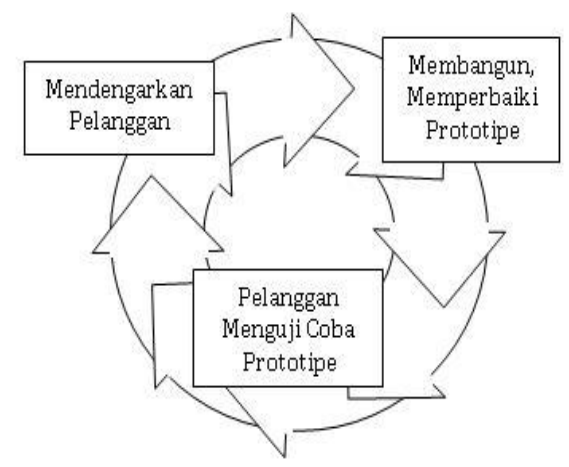

Gambar 1 Metode Prototype

Mendengarkan Pelanggan: developer dan klien bertemu dan menentukan tujuan umum, kebutuhan yang diketahui dan gambaran bagianbagian yang akan dibutuhkan berikutnya. Pada tahap ini penulis mengumpulkan data dan informasi dari sekolah menengah pertama guna merancang aplikasi pembelajaran matematika untuk jenjang sekolah menengah pertama.
Membangun, memperbaiki prototype: perancangan dilakukan cepat dan rancangan mewakili semua aspek software yang diketahui, dan rancangan ini menjadi dasar pembuatan prototype. Pada tahap ini, setelah mendapatkan data dan informasi yang dibutuhkan pengguna, penulis mulai merancang aplikasi sesuai dengan yang dibutuhkan pengguna, serta melanjutkan membuatnya menjadi aplikasi yang sesuai dan tepat guna.

Pelanggan Menguji coba prototype: pengguna mengevaluasi prototype yang dibuat dan digunakan untuk memperjelas kebutuhan software. Pada tahap ini, aplikasi yang telah dirancang dan dibuat, akan diuji guru, dan siswa sekolah menengah pertama untuk mengetahui kesesuaian aplikasi dengan kebutuhan pengguna.

\section{Hasil dan Pembahasan}

Tahapan pertama yang dilakukan adalah mendengarkan pelanggan dalam hal ini calon pengguna aplikasi. Hal ini bertujuan untuk mengetahui kebutuhan yang berkaitan dengan proses pembelajaran matematika khususnya pada kelas 7 SMP. Kegiatan dilakukan dengan cara perencanaan sebuah aplikasi yang akan dibuat dan diaplikasikan untuk para siswa kelas 7 SMP.

Setelah mendapatkan data dan informasi yang dibutuhkan pengguna, selanjutnya mulai merancang aplikasi sesuai dengan kebutuhan tersebut. Perancangan berfokus pada aspekaspek perangkat lunak yang akan nampak bagi pengguna, kemudian membangun atau memperbaiki program aplikasi yang di dalamnya telah berisi permintaan pengguna di tahap awal.

Pada tahap ini dibuat desain tampilan (interface) beserta fungsi-fungsinya yang kemudian diterjemahkan kedalam kode-kode dengan menggunakan bahasa pemrograman yang sudah ditentukan. Implementasi menggunakan Eclipse sebagai tools yang digunakan untuk mengaplikasikan bahasa pemrograman berbasis android. 
Use case diagram digunakan untuk mengetahui fungsi apa saja yang ada didalam sebuah sistem informasi dan siapa saja yang berhak menggunakan fungsi-fungsi itu seperti disajikan pada Gambar 2.

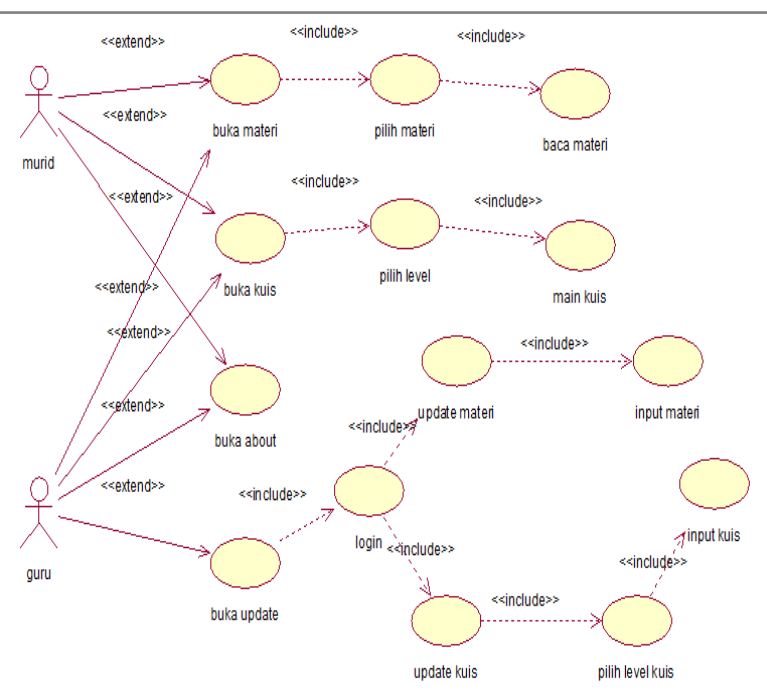

Gambar 2. Use Case Diagram Aplikasi

Pada tahap ini dijelaskan mengenai kebutuhan fungsionalitas serta mendiskripsikan sebuah interaksi antara aktor dengan aplikasi yang akan dibangun. Gambar usecase diatas menjelaskan bahwa tahap awal guru dapat membuka materi, kuis, aturan. Guru juga dapat mengupdate materi dan kuis. Siswa dapat melihat materi, kuis, dan aturan.

Sequence diagram menggambarkan kelakuan atau prilaku objek pada use case dengan mendeskripsikan waktu hidup objek dan pesan yang dikirimkan dan diterima antar objek (Gambar 3).

Pada sequence diagram Gambar 3, dijelaskan bahwa yang pertama kali dilakukan pada oleh siswa adalah melihat materi, mengerjakan kuis. Siswa membuka kuis, setelah muncul halaman level siswa memilih level yang akan dikerjakan. Pengerjaan akan disimpan dalam basisdata, setelah pengerjaan kuis akan muncul nilai dari pengerjaan kuis. Guru dapat mengupdate materi dan kuis.

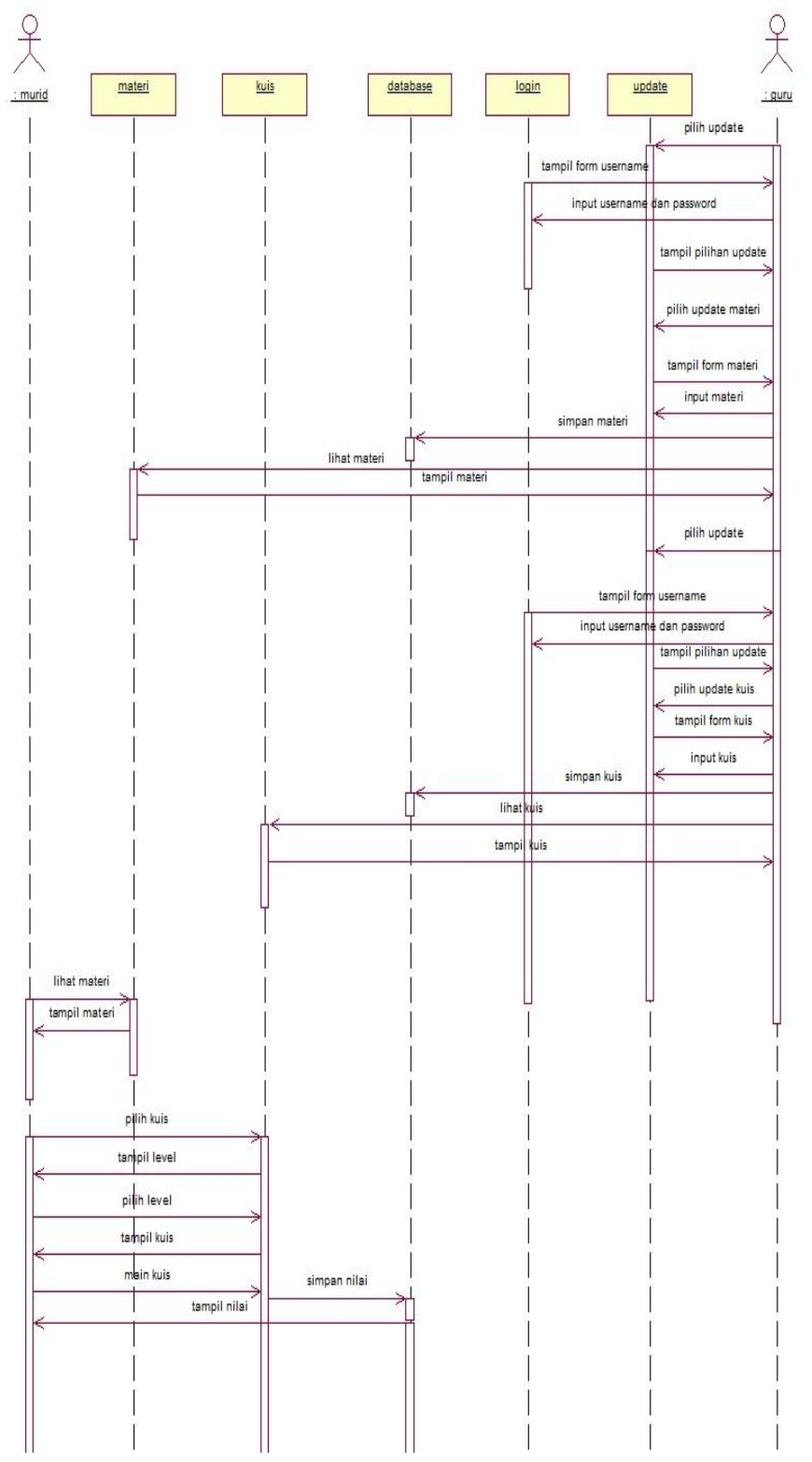

Gambar 3. Sequence Diagram Aplikasi

Rossa dan Shalaluddin (2013), mengatakan Class diagram atau diagram kelas menggambarkan stuktur sistem dari segi pendefinisian kelas kelas yang akan dibuat untuk membangun sistem. Kelas yang memiliki apa yang disebut atribut dan metode atau operasi.

Class diagram yang dibuat untuk membangun aplikasi pembelajaran disajikan pada Gambar 4. Dimana class main merupakan kelas yang menangani tampilan. Class soal, dan Class Materi merupakan tabel-tabel pada basisdata yang nantinya akan berisi field-field dari aplikasi. 
Materi terhubung dengan soal, Soal terdiri dari soal mudah, soal sedang, dan soal sulit yang terhubung dengan gambar mudah, sedang, dan sulit. Login update menghubungkan tabel soal materi dan level.

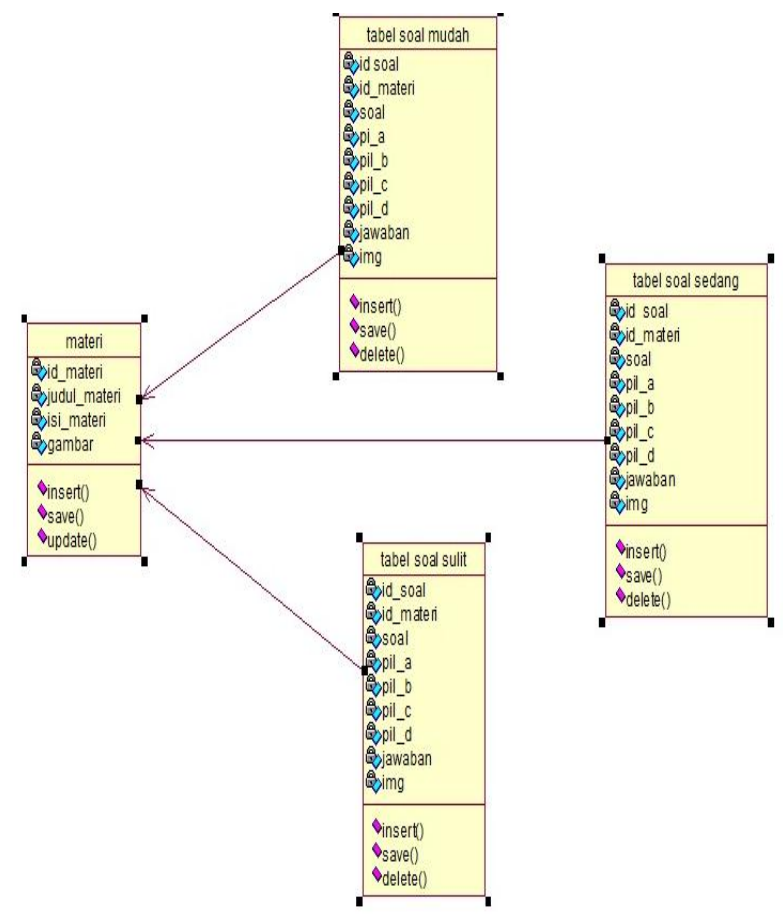

Gambar 4. Class Diagram Aplikasi

Setelah menyelesaikan semua tahapan perancangan, pembuatan aplikasi dilanjutkan dengan merancang tampilan aplikasi. Rancangan ini yang kemudian menjadi dasar pembuatan form tampilan aplikasi yang menjadi antarmuka bagi pengguna.

Form menu utama Gambar 5 merupakan tampilan pada saat pertama kali pengguna membuka aplikasi pembelajaran pelajaran matematika untuk siswa sekolah menengah pertama ini. Pada form ini juga pengguna sudah bisa mendengarkan latar lagu yang diputar otomatis dari awal hingga akhir oleh aplikasi yang diharapkan dengan musik tersebut pengguna bisa lebih relax saat pengerjaan kuis. Untuk memulai saat pengerjaan kuis pengguna terlebih dahulu untuk menekan tombol start.

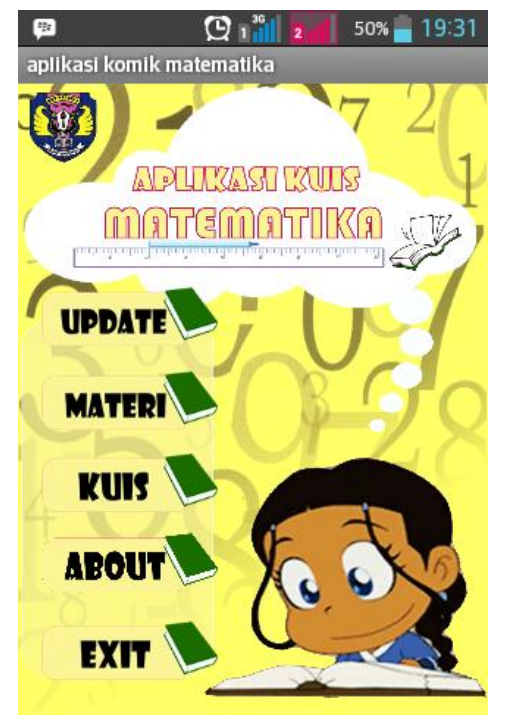

Gambar 5. Form Menu Utama

Form login pada Gambar 6, diperlukan untuk menentukan hak akses bagi pengguna yaitu sebagai guru atau siswa.

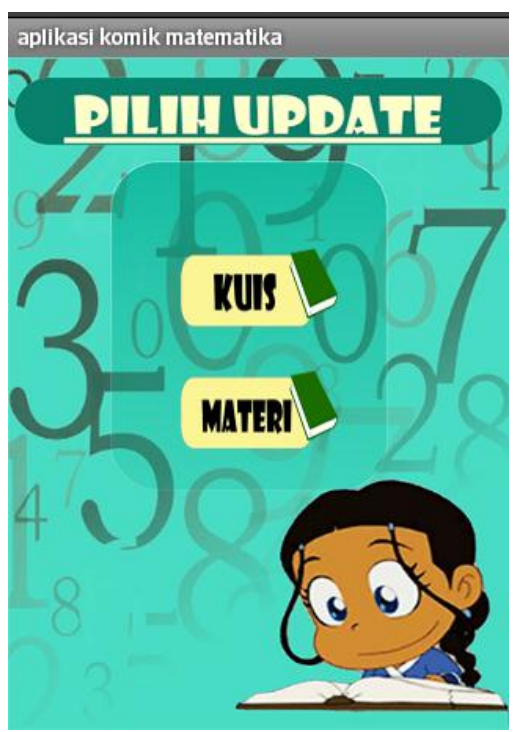

Gambar 6. Form login hak akses

Pengujian unit dilakukan setelah aplikasi pembelajaran telah selesai dibuat. Pengujian unit pada aplikasi ini dilakukan dengan cara error handling testing. Error handling testing digunakan untuk mengetahui sejauh mana aplikasi dapat mengantisipasi kebutuhan pengguna dalam menggunakannya.

Pengujian Black-Box berfokus pada persyaratan fungsional perangkat lunak. Pengujian black-box didesain untuk mengungkap kesalahan pada persyaratan fungsional tanpa mengabaikan 
kerja internal dari suatu program. Teknik pengujian black-box berfokus pada domain informasi dari perangkat lunak, dengan melakukan test case dengan mempartisi domain input dan output dari suatu program dengan cara memberikan cakupan pengujian yang mendalam. Hasil pengujian yang dilakukan menunjukkan aplikasi dapat berfungsi sesuai dengan kebutuhan pengguna.

Selain pengujian menggunakan metode black box, pengujian aplikasi ini juga dilakukan di SMP PGRI 1 Cluring Banyuwangi. Dengan penguji/responden sebanyak 10 orang, 1 guru mata pelajaran dan 9 siswa dari kelas 7. Melalui ujicoba tersebut dapat ditarik kesimpulan bahwa aplikasi pembelajaran ini dapat : membantu guru mata pelajaran matematika untuk menyampaikan materi agar lebih bisa dipahami oleh siswa; membantu siswa mempelajari matematika di luar sekolah; serta mampu meningkatkan motivasi belajar matematika bagi siswa dengan menyenangkan.

Soal-soal dan materi pada aplikasi pembelajaran matematika ini juga telah sesuai dengan kurikulum sehingga mampu diterapkan pada siswa SMP.

\section{Kesimpulan dan Saran}

Berdasarkan tujuan penelitian dan pembahasan yang dilakukan, dapat disimpulkan beberapa hal berikut : 1) Purwarupa Media Pembelajaran Matematika ini telah berhasil dirancang dengan menggunakan UML dan dibangun dengan bahasa pemrograman android; 2) Aplikasi ini terdapat materi dan kuis yang dapat diupdate oleh guru atau pengguna sesuai dengan kurikulum terbaru; 3) Dapat meningkatkan ketertarikan belajar siswa karena dilengkapi dengan gambar-gambar yang menarik pada kuis; 4) Berdasarkan hasil pengujian yang dilakukan aplikasi ini telah sesuai dengan kurikulum dan mampu membantu siswa agar lebih memahami materi yang telah disampaikan oleh guru di sekolah.

Adapun saran pengembangan sistem yang dapat dilakukan sebagai berikut : 1) Penggunaan mysql sebagai database karena database mysql dapat dijadikan sebagai server database secara online sehingga memudahkan dalam update materi dan kuis; 2) Penambahan fitur simpan nilai pada basisdata untuk membantu evaluasi hasil belajar siswa.

\section{Daftar Pustaka}

Arma, Atika. 2013. Aplikasi Pembelajaran Mengenal Angka, Bentuk Dan Warna Usia 4-5 Tahun Berbasis Android. UNIKOM. Bandung. http://elib.unikom.ac.id/ docjurnal/Atika_Arma-

jurnal_karya_ilmiah.pdf. Diakses Diakses pada tanggal 18 Juli 2014 pukul 21.06

Daryanto, 2004. Aplikasi Pembelajaran Komputer. Bandung: PT. Media Informatika

http://180.241.122.205/docjurnal/mirzajurnal karya ilmiah.pdf. Diakses pada tanggal 19 Juli 2014 pukul 07.03

http://repository.amikom.ac.id/files/Publikasi 08.1 2.2980.pdf. Diakses pada tanggal 25 Juli 2014 pukul 14.26

http://elib.unikom.ac.id/docjurnal/Vivi_Sumantijurnal_karya ilmiah.pdf.

Diakses pada tanggal 07 Juli 2014 pukul 12.14

Mirza, 2014. Pembuatan Game Kuis Matematika Dasar Berbasis Flash (Studi Kasus Pada Sd Banda Aceh). Stimik U'budiyah. Aceh.

Octaviady, Eggy. 2013. Pembangunan Game Edukasi Bahasa Inggris Dan Matematika Untuk Anak SD Kelas 3. UNIKOM. Bandung. http://elib.unikom.ac.id/docjurnal/Egy octavia dy-jurnal_karya_ilmiah.pdf.

Diakses pada tanggal 06 Agustus 2014 pukul 20.07

Pamuji, Eko. 2013. Pembuatan Aplikasi Pembelajaran Andromath Berbasis Android. STMIK AMIKOM. Yogyakarta.

Pangestu, 2013. http://www.pramsoftware.com/2013/05/Pengertian-Databasedan Perangkat-Lunak-software-Database.html Diakses pada 20 agustus 2014 pukul 04.14 wib

Permadi, Hendi Dhewa. 2013. Aplikasi Pembelajaran Kord Dasar Gitar Berbasis Android.

http://elib.unikom.ac.id/docjurnal/Dhewa Hendyjurnal karya ilmiah.pdf.

Diakses pada tanggal 16 Agustus 2014 pukul 10.15

Presman, Roger S., 2002. Rekayasa Perangkat Lunak Pendekatan Praktisi (Buku Satu). Yogyakarta : Andi 
Rahyubi, Heri. 2011. Teori-Teori Belajar Dan Aplikasi Pembelajaran Motorik. Bandung: Nusa Media

Rossa, A. S dan Shalaluddin, M. 2013. Rekayasa Perangkat Lunak Terstrutur dan Berorientasi Objek. Bandung : Informatika

Soedjadi, R. 2000. Kiat Pendidikan Matematika Di Indonesia. Jakarta : Direktorat Jenderal Pendidikan Tinggi, Departemen Pendidikan Nasional

Sumanti, Vivi. 2013. Pengembangan Sistem Informasi Akuntansi Laporan Keuangan Neraca Pada Klinik Mutiara Cikutra Dengan Menggunakan Pemodelan Uml. Unikom Bandung.

Supardi, Yuniar. 2014. Seтиa Bisa Menjadi Programmer Android. Jakarta : PT Elex Media Komputindo

Suprianto, Dodit. 2012. Pemrograman Aplikasi Android. Jakarta: PT. Buku Seru

Uno, Hamzah. 2011. Perencanaan Pembelajaran. Jakarta : PT Bumi Aksara 